\title{
Considering Art in a Hospital Environment from Children's and Young People's Perspectives
}

\author{
Kate Bishop \\ Faculty of Built Environment, \\ University of New South Wales, \\ Sydney, NSW 2052, Australia \\ k.bishop@unsw.edu.au
}

\begin{abstract}
In response to research evidence, (predominantly research with adults) the need for artwork in healthcare environments is now regularly part of the initial design briefs for hospitals. The resulting artwork can be a collection of commissions; it can also be included as a seamless extension of the interior design concept. In the case of paediatric hospitals, it is unlikely that 'art' which is simply a graphic treatment applied to key surfaces throughout the hospital environment, could function in the ways that children and young people have identified in research as being valuable in their experience of hospitalisation. This one environmental attribute will be used to understand some of the key components of a hospital environment involved in children's feeling of well-being from their perspectives.
\end{abstract}

Keywords: children; hospitals; art; health

eISSN 2514-751X @ 2017 The Authors. Published for AMER ABRA by e-International Publishing House, Ltd., UK. This is an open-access article under the CC BY-NC-ND license (http://creativecommons.org/licenses/by-ncnd/4.0/). Peer-review under responsibility of AMER (Association of Malaysian Environment-Behaviour Researchers), ABRA (Association of Behavioural Researchers on Asians) and cE-Bs (Centre for EnvironmentBehaviour Studies), Faculty of Architecture, Planning \& Surveying, Universiti Teknologi MARA, Malaysia.

https://doi.org/10.21834/aje-bs.v2i5.219 


\subsection{Introduction}

The therapeutic effects of art and the arts on individual well-being have been recognised for many centuries. Art has been installed in hospitals since the 14th century (Baron, 1995) and the need for artwork in healthcare environments is now regularly part of the initial design briefs for hospitals. Currently, art is often included as specific commissions for a new hospital or as touring exhibitions which are installed in the public spaces of the hospital environment (MacNaughton, 2007). It can also be included as a seamless extension of the interior design concept. Increasingly there is a sense that the role of art in a hospital may be more than a therapeutic one; it may also function as a cultural resource for the surrounding community (MacNaughton, 2007).

What constitutes art has been the subject of debate for as long as art has existed and in modern hospitals it varies enormously from commissioned works by many individual artists to graphic treatments of key surfaces carried out by one artist and spanning the whole hospital. The reality of the final effect will necessarily be very different. One is likely to be full of quirkiness and dissimilarity whilst the other approach will lead to a seamless veneer that blends well with the surrounding context. A key question is how does this variation in approach to what constitutes art in healthcare settings potentially impact on patient experience? Is there likely to be a difference in the role of the art resulting from both approaches in patient satisfaction and well-being?

This paper will examine the findings from a qualitative study carried out with children and young people in a paediatric setting in which art was one of the environmental attributes that patients discussed and considered significant in their overall response to the hospital environment. The findings from this study suggest that idiosyncratic collections of art that stand out in the hospital context provide sources of entertainment and engagement that are crucial to children's positive response to the hospital environment and to their feeling of well-being whilst in it. The idiosyncratic selection also allows for a range of contributors including children themselves. In this study, children's art was particularly valued by children as it indicated a child-friendly organisation which was interested in having their involvement in the creation of the environment.

\subsection{Literature Review}

At present, there is only a small body of research into the effects of art on patient experience and health outcomes, or on the effects of art on staff responses to the hospital as a work environment. Studies focused on the experience of children and young people are the least well represented. The evidence that exists supports the inclusion of art in healthcare environments because it assists in health promotion and patient well-being (Caspari, Erikson \& Naden, 2006; Lawson \& Phiri, 2000; Lawson, Phiri \& Wells-Thorpe, 2003; Scher, 1996; Schweitzer, Gilpin \& Frampton, 2004; Ulrich, 1991, 1992, 2001); it positively affects medical outcomes (Duncan, 2003; Staricoff \& Loppert, 2003; Ulrich, 
Lunden \& Eltinge, 1993) and it reduces the stress of patients and staff and increases the satisfaction of both with the hospital environment (Homicki \& Joyce, 2004; Staricoff, Duncan, Wright, Loppert \& Scott, 2001).

The research on art with children and young people in health care settings is very limited. In environments for adolescents, it has been found to be important that the artwork is age-appropriate and does not include blatant emblems of childhood such as cartoon characters, clowns, balloons and teddy bears (Blumberg \& Devlin, 2006; Liabo, Curtis, Jenkins, Roberts et al., 2002; Tivorsak, Britto, Klosterman, Nebrig \& Slap, 2004). Adolescents require less permanently fixed art and more provision to add their own posters and artwork to their areas in healthcare settings (Blumberg \& Devlin, 2006). Research with children and young people in or about healthcare settings consistently shows their appreciation for bright, colourful décor and artwork is usually part of this assessment (Blumberg \& Devlin, 2006; Hutton, 2002, 2003, 2005; Sharma \& Finlay, 2003; Tivorsak et al., 2004). A growing body of research also indicates that the arts can play a significant role in providing psychological and emotional support for children who are in hospice care or who are experiencing the death of a family member in hospice care (Bertman, 1999; Graham-Pole, 2000; Samuels \& Lane, 1998; Rollins, 2002; Silverman, 2000; Sourkes, 1995).

In summary, the research that exists establishes art as an influential element in patient satisfaction and healing but there is limited research in this area and most of it has involved adult patients. The understanding of the roles of art in patient experience and healing lacks depth and sophistication at present, which undermines the knowledgeable inclusion of this attribute in healthcare settings. This is particularly the case in paediatric settings.

\subsection{Methodology}

The current study was a participatory qualitative case study completed with children and young people aged 9-18 years, at the Children's Hospital at Westmead in Sydney, Australia in 2008. The aims of the research were firstly to understand what constitutes a supportive paediatric setting from children and young people's perspectives, secondly to describe the roles of the physical environment in children's feeling of well-being and thirdly, to illustrate the value of participatory research to healthcare design. The findings of this study were broader than the focus of this paper, however a discussion centred on the role of art in this study will provide a useful lens through which to understand the broader findings.

The study was comprised of four stages. These included: 1) two pilot studies, 2) main study data collection, 3) data analysis and 4) interpretation and conclusions. Fifty five children and young people aged 7-18 years were involved in the four stages of the study. Twenty four of these were involved in pilot studies, including nine boys aged 7-16 years and 15 girls aged 7-18 years. Thirty one participants were involved in the main study, 
including 13 boys aged $9-17$ years and 18 girls aged 10-18 years. Participants in the main study had to have been admitted to the hospital for at least seven days at the time they were interviewed. Within the main study, children and young people were asked to complete a single interview which consisted of three tasks. Task A included an informal discussion centred on a set of photographs of the Hospital environment taken by participants in the second pilot study, Part A. Task B involved answering a set of 30 questions spanning the possible domains and dimensions of children's experience of hospitalisation and well-being derived from both the literature and the findings from the pilot studies. Task $\mathrm{C}$ involved a game task which functioned as a consistency check within each interview. The interviews resulted in three sets of data including two sets of narrative data from tasks $A$ and $B$ which were analysed using concept mapping and thematic analysis techniques and the game task results, which required tallying. The results from each of the three data sets were triangulated to create preliminary findings. These preliminary findings were developed into a series of statements and summaries that were then taken back to a group of six patients who were representative of the profile of participants in the main study for further discussion as part of a member-checking task, before the final conclusions were reached.

\subsection{Research Findings}

The findings from this study indicate that art was a key environmental attribute which had a number of functions in children's hospital experience. These included: providing a rich source of aesthetic variation, entertainment, distraction, engagement and identity which supported young people's capacity to maintain a positive frame of mind and remain positively engaged in their experience; providing indications of a 'child-friendly' and appropriate environment for children, to children; providing an opportunity for children to feel supported by other children who had been involved in the creation of the environment; providing a rich source of colour; and finally assisting the environment in "not looking like a hospital" which became increasingly important to children and young people with time. No real variation was found between the responses of younger and older children in this study. Providing a rich source of aesthetic variation, entertainment, distraction engagement and identity supported young people's capacity to maintain a positive frame of mind and remain positively engaged in their experience. Both remaining engaged and maintaining a positive frame of mind were identified as fundamental elements in children's and young people's feeling of well-being in hospital in this study. The quotes below provide insight into the participants' response to the art.

Participant: $\quad$ Yeah I think all the brightness in this hospital really does make a difference. I love all the artwork everywhere. There's um a famous artist right at the front of this ward, maybe it's Paul, maybe it's Klee? He's an Australian artist and it's really impressive. 
Researcher: What difference do you think it makes having artwork and colour?

Participant: Um I think like thinking of colour therapy and stuff, I think colour does something to your mind like if I was in a room that was all orange I would tend to be more happier than if the room was just the grey colour. Yeah so I think colour influences your moods. (Lana, 181)

Researcher: Now you said you notice the paintings. Does it make a difference having them?

Participant: $\quad$ Yeah for sure yeah. Like it's variation, you know? The fact that each corridor doesn't look the same is a real big difference. That's one thing why the floor bothers me 'cause the floor looks the same everywhere and 'cause you're in here for, sometimes you're in here for a long time and you know change is really important. You know it keeps you

- 'cause for me health is not just physical it's mental so if you're happy and you're in a nice looking place you'll be healthier you know? (James, 17)

Researcher: Ok now you've said you noticed the pictures and sculptures around the Hospital, do you think they make a difference?

Participant: Yep a lot

Researcher: What's the effect of them?

Participant: It's just like it doesn't make you feel like you're in a gaol or something, or closed into a place and you're not allowed out or it just kind of gives you, I don't know, some kind of feeling like you can always like um get like a feeling or um you know an idea from a painting or sculpture, and it makes you react to it and it's just something that adds a little touch to the Hospital. It's good. There's heaps of colour like because of the statues they put up and the paintings that have been brought in, just like add to the Hospital to make everyone more comfortable in it so it's a really nice environment, I enjoy it. (Polly, 14)

For children and young people in this study, the aesthetics of the hospital environment, (of which art is identified as a key component) is one of three key elements used by children and young people in their assessment of the appropriateness of a hospital environment for them. The other two include the volume of age-appropriate activities and the welcome they received from the Hospital community. Together, these three components were consistently used by children and young people to estimate the 'childfriendliness' of the environment. The quotes below discuss the colour and artwork in the Hospital for the perceived message of welcome that they impart:

Researcher: Ok you said you notice pictures and sculptures on the way around, do you think it makes a difference having them?

Participant: $\quad$ Yes it allows us as the kids to um, to make connection for a minute to people who have made the artworks. Like it helps us to um, to sort of like to interact with the Hospital. Makes us feel like um we're welcomed and we're um we're, it's like um....that we, it's a good place 
to be here. It makes like the atmosphere a good atmosphere. Like there's always pictures everywhere, they're always happy and they make you smile all the time. (Justin, 15)

Yes I think it's a nice hospital. I have visited people in other hospitals and it's nowhere near as nice as this one. This hospital doesn't smell like a hospital, it doesn't look like a hospital from the outside um in the inside it's very colourful and lots of pictures and artwork and I think it just makes it a nice place to be in. Like it's not nice to have to be here but it makes it nicer having the um, artwork and the colours and everything. I think it would help people to find it more, like more like home and more comforting. (Sarah, 15)

Participant: $\quad$ Yeah this is a good place for kids.

Researcher: And what makes it that?

Participant: Um the colours and the activities that they have for kids and the general way that um doctors and staff treat kids. I think they're very friendly, they're more friendly towards them and very...like how you play with kids and you're bright around them. (Lana, 18)

The artwork in the environment that was completed by children and young people themselves was particularly valued and potent as it was seen as messages of support left behind by one group of children for others. It was also seen as an indication that the organisation itself valued children as it had allowed them to be involved in the creation of the environment. The presence of this artwork in the Hospital represented an overt message to children and young people that their welfare and needs mattered to the organisation. The artwork was perceived as an indication that the organisation was childfriendly and was a part of the environment's message of welcome for children and young people. It also gave them a sense of ownership of the environment as reflected in the comments below:

Researcher: What do you think you notice when you move around the hospital?

Participant: All the pictures, like that people have painted, that kids have painted.

Researcher: Does it make a difference that kids have painted them?

Participant: Yes I reckon it does.

Researcher: What sort of difference does it make?

Participant: I think 'cause it's like you know people getting involved with the Hospital and it makes it brighter and it gives you something to look at. (Milly, 11)

Researcher: What do you think you notice as you walk around the environment?

Participant: I notice that there's lots and lots of pictures that are done by kids.

Researcher: That's a good thing? Or it's not? Or...?

Participant: That's a good thing, a very good thing. I think it's great that you just haven't stuck some famous person's artwork up there; that kids actually got to be involved in the artwork. (Sarah, 15) 
Participant: ' Cause I don't like that I have to be here, I like it, but I would prefer not to be here, so, but being here I like the environment.

The institutional feel of the hospital became increasingly important to children and young people as the time they spent in the environment increased. 'Not looking like a hospital' was also key in alleviating the impact of having to spend a lot of time in the environment. Environmental attributes such as colour, light and artwork, are acknowledged by children and young people as helping to provide an atmosphere of welcome and comfort and to undermine the identity of the building as a hospital which became increasingly important across time. This is reflected in the discussion below:

\begin{tabular}{|c|c|}
\hline Researcher: & And what would you say you like about it? \\
\hline Participant: & $\begin{array}{l}\text { I like the colours, I like the artwork, um I like it that it's not just like row } \\
\text { after row of corridors and rooms um it's got some movement in the } \\
\text { structure. Um I like the gardens and how there's that Chinese garden, } \\
\text { from a different country. Interesting to see what a garden would be like } \\
\text { in another country. Um I also think that if you didn't know that this was } \\
\text { a hospital you probably wouldn't think it was one, I think that the } \\
\text { designer did a very good job of that, making it not look like a hospital. }\end{array}$ \\
\hline Researcher: & $\begin{array}{l}\text { And what kind of difference do you think that makes? That is doesn't } \\
\text { look like a hospital? }\end{array}$ \\
\hline Participant: & $\begin{array}{l}\text { Um I think....it's not like ugly and those square things with rows of } \\
\text { windows and it's like that, 'this is this awful skyrise building that I have } \\
\text { to go to'. It's more, it's like flowing and maybe, it's nice to look at and } \\
\text { maybe even be there with knowing that you're not in this square } \\
\text { building with rows and rows of windows. (Sarah, 15) }\end{array}$ \\
\hline
\end{tabular}

\subsection{Discussion}

There is already consensus among researchers that the environmental aesthetics of healthcare environments are important to patients' feeling of well-being (Caspari, Erikson \& Naden, 2006; Olds, 1991; Ulrich, 1991, 1992, 2001). The central argument is that creating aesthetically pleasing environments will contribute to patients' well-being by influencing their emotional response to the experience and environment (Caspari, Erikson \& Naden, 2006). The findings from this study would support this. The perceived pleasing aesthetics that children and young people acknowledge in this hospital environment provokes a positive response and connection with the environment and alleviates the emotional stress of the experience of hospitalisation.

At the Children's Hospital at Westmead, the artwork varies constantly around the walls and corridors. It is an eclectic mix of paintings, photographs, sculptures, professional work, children's work and temporary installations. The collection is appreciated as a source of constantly changing sensory stimulation. Olds (1991) discussed a concept called 
difference-within-sameness. She cited natural examples as the ultimate definition of this concept - a babbling brook, wafting breezes, sunlight dancing on leaves. The concept centres on the notion of the need to experience variation in sensory stimuli to enable constant attention and engagement in an environment, even if it is variation within sameness. This means that even if the feature does not change radically as it unfolds, such as the brook itself, the visual and auditory play of the water over the stones on its way is enough to provide renewed sensory interest for the observer. The findings from this study indicate that the artwork in this hospital is appreciated by patients in a similar capacity. Because the art varies constantly within the environment, it demands the attention of passersby which enables it to function, at the very least, as a distraction and often, as much more than this in patients' experience.

Again, because the art varies constantly around the environment, it builds an expectation of change within the environment which sustains patients' and their families' interest in the experience and environment of the Hospital. Children and young people in this study stressed the need to stay occupied and positively engaged whilst in hospital to reduce the likelihood of becoming bored and feeling down about their situation and participants acknowledged the art in this role. Environmental variation and difference were vitally important to the children and young people in this study as these characteristics had the capacity to help them stay engaged and interested in the environment across time. Becoming bored was feared by most of the participants because it was closely linked to 'feeling down' about themselves and their situation which had the effect of prolonging time and creating dissatisfaction and discomfort with the experience of hospitalisation. The eclectic nature of the Hospital's art collection functioned as an unobtrusive, undemanding source of variation and change that was accessible and nourishing for many patients and their families. It stood out in stark contrast to the interior context of the hospital corridors and spaces and was eye catching, promoting children's engagement. It also meant, as acknowledged by children, that the artwork helped with their orientation and wayfinding within the environment because there was no repetition of decor or art throughout the environment and pieces of art work could function as landmarks.

\subsection{Conclusions}

In all of the roles for art discussed in relation to this study, what was consistently valued by children and young people was the eclectic nature of the artwork in this environment. This finding supports a recommendation for treating the hospital setting as a gallery space rather than a residential space; allowing the disjunct that will occur between some artwork and the building itself to be seen as positive in patient experience in paediatric settings rather than as a negative on aesthetic grounds. It is difficult to see how artwork that is included as a seamless extension of the interior design concept would be able to function in the same ways in children's experience as identified in this study. It is not unreasonable to suggest 
that artwork that is made to blend in with the rest of the interior decor is less likely to registeras varying and as a positive source of distraction in the environment in children's perception. Whilst the regular inclusion of art in health care environments is by nature likely to be a good thing as it will lead to a more aesthetically rich environment which is valued by children and young people, this study reveals that it is possible for art to play many more roles in children's and young people's experience of hospital environments if these are understood and acknowledged by the creators of paediatric hospitals.

\section{Acknowledgements}

I would like to thank the children and young people at the Children's Hospital at Westmead for their willing cooperation and also the wider hospital community for their assistance in completing this study.

\section{References}

Baron, J. H. (1995). Art in Hospitals. Journal of the Royal College of Physicians, 29, 131-142.

Bertman, S. (1999). Grief and the healing arts: creativity as therapy. Amityville, NY: Baywood.

Bishop, K.G. (2008). From their perspectives: Children and young people's experience of a paediatric hospital environment and its relationship to their feeling of well-being. Unpublished doctoral dissertation, The University of Sydney, Sydney.

Blumberg, R., \& Devlin, A. S. (2006). Design issues in hospitals: The adolescent client. Environment and Behavior, 38(3), 293-317.

Caspari, S., Eriksson, K., \& Naden, D. (2006). The aesthetic dimension in hospitals: An investigation into strategic plans. International Journal of Nursing Studies, 43, 851-859.

Duncan, J. (2003). The effect of colour and design in hydrotherapy: designing for care. In D. Kirklin \& R. Richardson. (Eds.) The Healing Environment. (pp. 81-100). UK: Royal College of Physicians.

Graham-Pole, J. (2000). Illness and the art of creative self expression. Oakland, CA: New Harbinger.

Homicki, B. \& Joyce, E. K. (2004). Art illuminates patients' experience at the Massachusetts General Hospital Cancer Center. The Oncologist, 9, 111-114.

Hutton, A. (2002). The private adolescent: Privacy needs of adolescents in hospitals. Journal of Pediatric Nursing, 17(1), 67-72.

Hutton, A. (2003). Activities in the adolescent ward environment. Contemporary Nursing, 14(3), 312-319.

Hutton, A. (2005). Consumer perspectives in adolescent ward design. Issues in Clinical Nursing, 14, 537-545. 
Lawson, B. \& Phiri, M. (2000). Room for improvement. Health Science Journal, 24, 20-23.

Lawson, B., Phiri, M., \& Wells-Thorpe, J. (2003). The architectural healthcare environment and its effects on patient health outcomes. Norwich, England: TSO.

Liabo, K., Curtis, K., Jenkins, N., Roberts, H., Jaguz, S., \& McNeish, D. (2002). Healthy futures: A consultation with children and young people in Camden and Islington about their health services. London: Camden \& Islington NHS Health Authority.

MacNaughton, J. (2007). Art in hospital spaces: The role of hospitals in an aestheticised society. International Journal of Cultural Policy, 13 (1), 85-101.

Olds, A. R. (1991). With children in mind: Novel approaches to waiting area and playroom design. Journal of Healthcare Interior Design, 3, 111-122.

Rollins, J.A. (2002). ART is the heart: A palette of possibilities for hospice care. Pediatric Nursing28 (4), 355-364.

Samuels, M., \& Lane, M. (1998). Creative healing. New York: Harper

Scher, P. (1996). Patient focused architecture for health care. UK: The Manchester Metropolitan University.

Scher, P. \& Senior, P. (2000). The Exeter evaluation. Exeter, UK: Royal Devon and Exeter Hospital.

Schweitzer, M., Gilpin, L., Frampton, S., (2004). Healing spaces: Elements of environmental design that make an impact on health. The Journal of Alternative and Complementary Medicine, 10 (1) 71-83.

Sharma, S., \& Finlay, F. (3003). Adolescent facilities: The potential...adolescents' views were invited in the planning of a new unit, but to what extent were their suggestions incorporated? Paediatric Nursing, 15(7), 25-28.

Silverman, P. (2000). Never too young to know: Death in children's lives. New York: Oxford University Press

Sourkes, B. (1995). Armfuls of time: The psychological experience of the child with a life-threatening illness. Pittsburgh: University of Pittsburgh Press.

Staricoff, R. L., Duncan, J., Wright, M., Loppert, S., Scott, J., (2001). A study of the effects of the visual and performing arts in healthcare. Hospital Development, 32, 25-28.

Staricoff, R. L., \& Loppert, S., (2003). Integrating the arts into health care: Can we affect clinical outcomes? In D. Kirklin \& R. Richardson. (Eds.), The healing environment: without and within. (pp. 63-79). UK: Royal College of Physicians.

Tivorsak, T. L., Britto, M. Y., Klosterman, B. K., Nebrig, D. M., \& Slap, G. B. (2004). Are pediatric practice settings adolescent friendly? An exploration of attitudes and preferences. Clinical Pediatrics, 43(1), 55-61.

Ulrich, R. S. (1991). Effects of interior design on wellness: Theory and recent scientific research. Journal of Healthcare Interior Design, 3, 97-109.

Ulrich, R. S. (1992). How design impacts wellness. Healthcare Forum Journal, 35(5), 20-25.

Ulrich, R. S. (2001). Effects of healthcare environmental design on medical outcomes. In A. Dalani (Ed.), Design and health: The therapeutic benefits of design (pp. 49-59). Sweden: Swedish Building Council. 
Ulrich, R. S. (2000). Evidence based environmental design for improving medical outcomes. Paper presented at the Healing by design: Building for healthcare in the 21 st century, McGill University Health Center National Conference, Montreal, Canada, September 2000.

Ulrich, R.S., Lunden, O., Eltinge, J. L., (1993). Effects of exposure to nature and abstract pictures on patients recovering from heart surgery. Psychophysiology, 30, (Supp1) 7. 